A paper presented at the 29th Annual Convention of the American Instilute of Electrical Engineers, Boston, Mass., June 27, 1912.

Copyright, 1912. By A. I. E. E.

(Subject to final revision for the Transactions.)

\title{
THE WIRING OF LARGE BUILDINGS FOR
} TELEPHONE SERVICE.

\author{
BY FREDERICK L. RHODES
}

In modern office buildings, hotels and apartment houses large numbers of telephones are required. It would be inconvenient and impracticable to run a pair of wires through one of these large buildings each time a telephone is installed, in order to establish connection with the outside wire plant of the telephone system, as is ordinarily done when telephones are installed in residences or small business buildings. To overcome this difficulty, when the plans are prepared for an office building, hotel or apartment house, a forecast should be made of the probable future requirements of the building as a whole for telephone service, and facilities provided for a certain amount of cabling with the necessary terminals and subsidiary wiring. All large cities contain many buildings that are cabled and wired for telephone service according to a comprehensive plan and, of the smaller places, there are few that do not have some buildings of a character requiring more or less provision of this kind.

Building Plans Should Include Provision for Telephone Wiring. Owing to the type of building construction generally employed, and the large number of telephones to be served, unless suitable facilities are provided in advance for accommodating the cables and wires, and for running them through the walls and floors, the work will either be unsightly in spite of all precautions to the contrary, or expensive and costly alterations will be required after the completion of the building to enable the wires to be effectively concealed.

It is therefore of prime importance to owners and architects that, in preparing plans and specifications for office buildings, 
hotels or apartment houses, suitable arrangements should be made for such telephone wiring and terminal boxes as the character and use of the building will demand. As every large building to a certain extent presents problems of its own, advantageous and economical arrangements can frequently be suggested by those who are specially familiar with work of this kind. It is to the advantage of telephone companies as well as building owners to have adequate facilities provided for the cables and wires, and telephone companies are glad to place their experience freely at the disposal of those who are planning the erection of buildings that require special provisions to be made. It is now the general custom for architects to send for the telephone company's experts in these matters to give them such information as they need to plan this work in the best way. Classification of Buildings. In the following pages are described the general methods that have proved satisfactory for wiring buildings for telephone service. From this standpoint buildings may be divided into two classes:

1. Office and loft buildings.

2. Hotels and apartment houses.

The conditions that make a broad distinction between the two classes. are these: In office and loft buildings the telephones do not remain fixed either in number or location for any extended period, varying with the requirements of the individual tenants who will use more or less of the telephone service according to their respective kinds of business. In hotels and apartment houses the number of telephones is fairly definitely fixed, being almost invariably one for each room in a hotel and one or two for each apartment in an apartment house.

The office or loft building requires a permanent cable system supplemented by a multitude of branches consisting of pairs of wires whose function it is to connect the individual telephones or private branch exchange switchboards with the permanent cable system. This permanent backbone of cable extends upward from the basement, branching out and terminating at suitable distributing points on the several floors. These distributing points or cable terminals must be sufficiently numerous and so located that the changing requirements of the tenants can readily be met by running individual pairs of wires as needed to connect the telephones with these terminals.

It is, therefore, apparent that an office building must have a more comprehensive and flexible system of wiring than a hotel 
PLATE LXXXVI

A. I. E. E.

VOL. $X X X I$, NO. 7

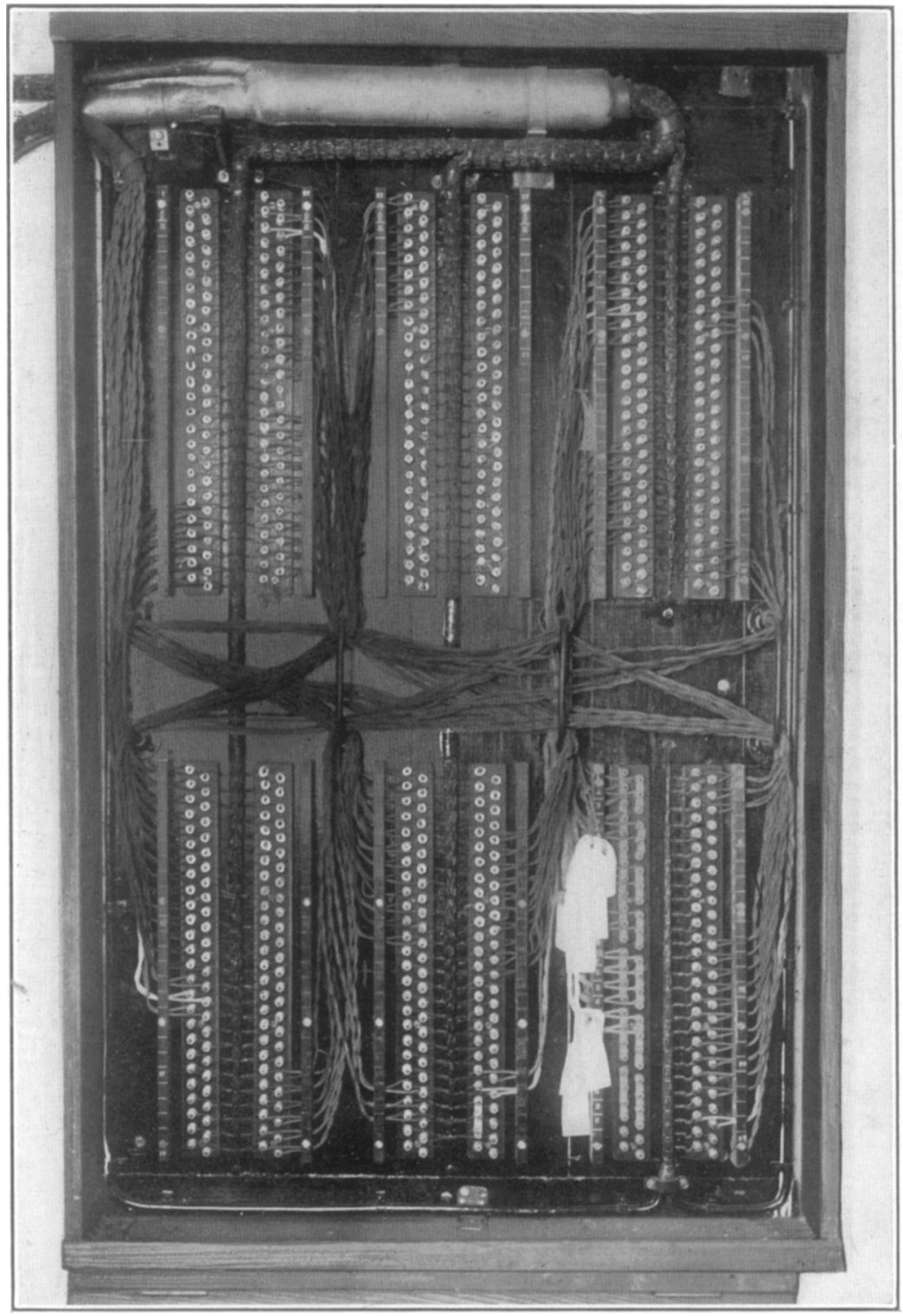

Fig. 1.-Main Terminal Box, Capacity for Terminating [rhodes 312 Pairs OF Wires.

The sliding door is removed to show the cross-connecting wires between pairs in the feeder cable and the house cable. 

or apartment house on account of the different character of the telephone service required. In the office building only a portion of the wiring system is permanent. In a hotel or apartment house practically all of the wiring is permanent.

\section{Office Buildings}

General Scheme of Wiring. In large office buildings one or more cables from the nearest telephone central office are brought to some convenient point, usually in the basement of the building. At this point the house cable system begins. A main terminal box (Fig. 1) is furnished and placed by the telephone company at this point so that cross-connections can be made as required between pairs in the house cables and pairs in the central office cables.

These main terminal boxes in the case of large buildings are necessarily somewhat bulky and the question of the size of the box that will be needed in any particular case may well be taken up with the telephone company by the architect or builder in order that sufficient space for it can be provided in a convenient and appropriate location at the foot of the riser shaft or conduit as the case may be. A dry, clean and accessible place should be selected. In some sections of the country, where buildings are in localities subject to floods, it will be well to provide space above the basement so that the telephone service will not be interrupted due to water getting into the basement.

From the main terminal box one or more riser cables are run to the top of the building. The riser cables gradually diminish in size as they extend up through the building. From the riser cables, subsidiary or branch cables of proper size are taken to distributing centers on the several floors. The locations of these centers should be chosen so as to admit of the shortest practicable wire runs to the offices, without making objectionable work necessary to conceal the wires.

Each subsidiary cable ends in a subsidiary terminal box, the purpose of which is to enable connections to be made readily between the cable and the individual pairs of wires that are run to each telephone. These subsidiary terminal boxes when placed by the telephone company are fastened against the walls of corridors near the ceiling and constitute the ends of the permanent wire system. Not infrequently the owner of the building desires to own the subsidiary terminal boxes in order that he may provide recesses for these boxes and small doors to match the trim of 
the building so that the boxes will be concealed from view. Where the boxes are built into the walls it is important that they should be of ample capacity on account of the trouble and expense that would result if they should prove inadequate and have to be replaced. It is customary to allow a greater margin for growth where the boxes are built in than where they are merely
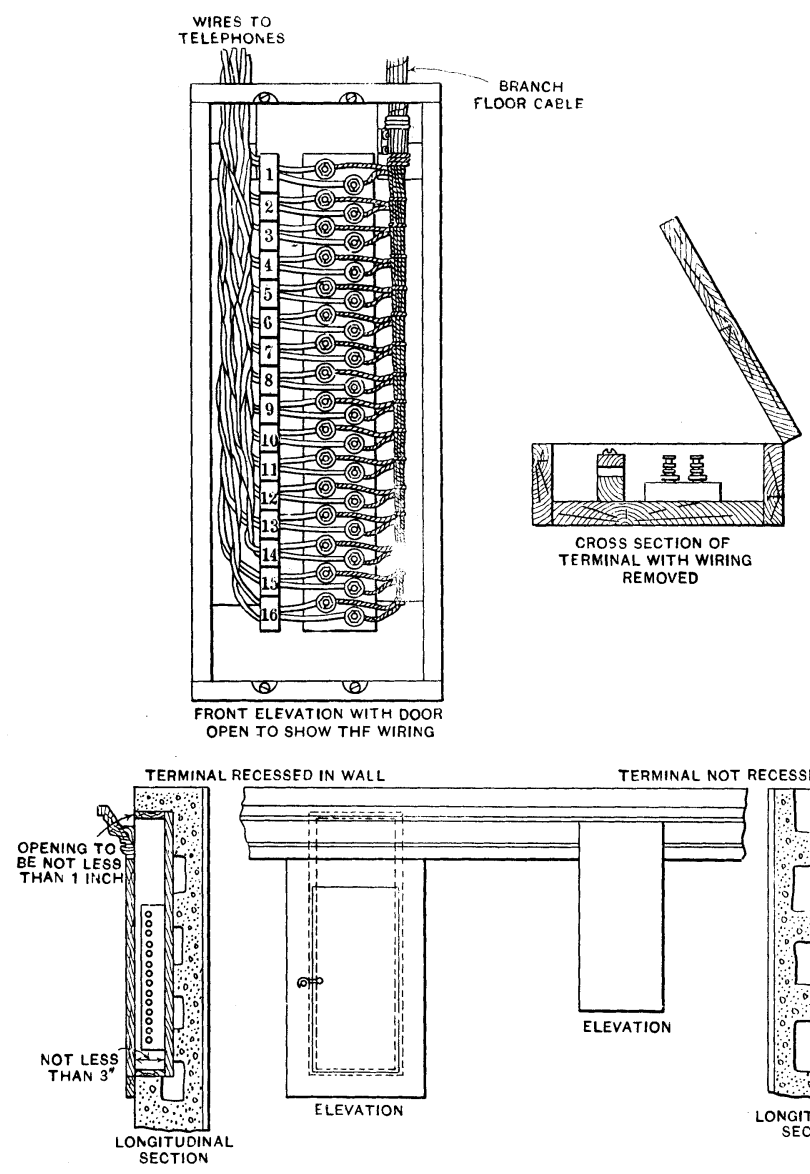

TERMINAL NOT RECESSED
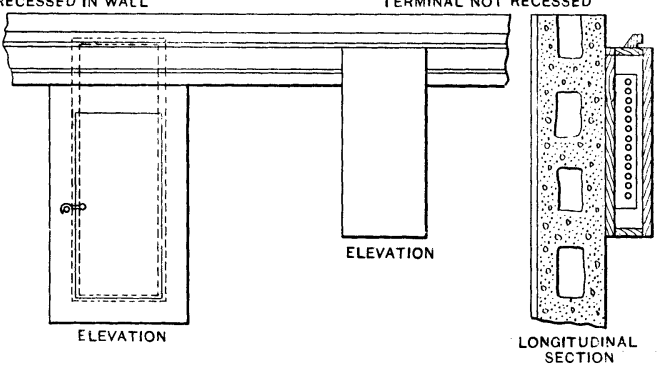

Fig. 2.-Subsidiary Terminal Box-15 Pairs.

fastened against the wall. Where a conduit system has been installed on the various floors for the purpose of distributing wires to each office, the subsidiary terminals are located at the centers of the conduit system. Fig. 2 shows a subsidiary terminal box, recessed in a corridor wall, under the molding, and also a subsidiary box placed against the wall under the molding. 
Forecasting the Number of Telephones. In forecasting the number of telephones that will probably be required in an office or loft building, the principal factors to be taken into account are the "renting floor area" of the building and the character of the business district in which it is situated, with special reference to its proximity to railway terminals, important streets and business centers.

Buildings in the financial district of a city ordinarily demand more telephones per unit of floor area than do buildings located in the commercial districts. In computing the "renting floor area," only the office floor space is considered; hallways, elevator shafts and light wells are omitted. In all cases a safe margin for growth must be allowed. The following table shows rough average figures for telephonic density in office and loft buildings, based on a large number of cases:

\begin{tabular}{|c|c|c|} 
Kind of building & Character of district & $\begin{array}{c}\text { Pairs of telephone wires } \\
\text { per } 1000 \text { sq. } \mathrm{ft} . \\
\text { of renting area }\end{array}$ \\
\hline Office & $\begin{array}{c}\text { Financial } \\
\text { Commercial } \\
\text { Loft }\end{array}$ & $\begin{array}{l}4 \text { to } 5 \\
2 \frac{1}{2} \text { to } 3 \frac{1}{2} \\
1 \text { to } 2\end{array}$
\end{tabular}

Size of Riser Cables. By basing the size of the riser cables on the renting area and the expected telephonic density as influenced by the character of the locality (checking this by a study of the probable number of offices and the requirements of prospective tenants) the cable system for any office or loft building may be planned with reasonable assurance that provision will be made for the maximum service required. On account of the requirements for battery feed wires and ringing current for private branch exchanges, the riser cables necessarily contain more pairs than do the cables that run from the building to the telephone central office.

Shafts or Conduits for Riser Cables. In buildings over 12 stories in height or in buildings of less height, where large riser cables are required, it is preferable to place the riser cables in suitable shafts rather than in conduits, as the advantage of having the cable protected by conduits is offset by the difficulty of installing and properly fastening the large cables in the conduits and making large complicated splices in the junction boxes that are required with a conduit system. 
If properly installed a conduit system is the best equipment for buildings less than 12 stories in height where small cables are to be placed, as the cables are effectually protected against injury. It is important, however, to remember that the success of a conduit system for installing vertical cables depends entirely on a perfect installation. The conduits must be of proper size and if possible free from bends. If bends are absolutely necessary, they should be made with a radius not less than three feet. The junction boxes at splicing points must be at least two feet square and the conduits must enter the boxes adjacent to a side in order that the cable may be bent and placed in a horizontal position for splicing.

Cable Shafts. Cable shafts should extend from the basement of the building to the top floor and should be easily accessible at each floor for the placing and splicing of the cables. Usually the shaft can best be located in a corridor partition, or in the wall of some public space leading out from the corridor, so that an opening can be made into the shaft from the corridor and covered with removable paneling or doors.

It is desirable to have a separate shaft for telephone cables and wires, as the placing of steam. water or gas pipes and light and power wires in the same shaft with the telephone cables renders the latter liable to injuries that may result in interrupting the telephone service.

Underground Cable Entrance to Building. Repairing basement walls and their waterproofing, due to the necessity for cutting through them, can be avoided if architects will specify a three-inch iron pipe sleeve for each ultimate underground cable entering the building, these sleeves extending through the wall at the point of entrance. The location of the point of entrance should be taken up with the telephone company in order that it may suitably fit in with the underground conduit system outside the building.

Junction Boxes. Riser cables ordinarily diminish in size as they go up the building. When a building is provided with conduits for both riser and subsidiary cables the conduit may diminish in size in the vertical section in the same relative manner as it is proposed to diminish the riser cable. Where a separate conduit is installed for each subsidiary cable a splice is required between the subsidiary and the main cable and a junction box is required wherever one of these splices must occur. These boxes should be approximately 24 inches square by five inches 
deep (inside dimensions) in order to enable the splices to be properly made and stowed away. In a system of this kind the subsidiary cables and the sections of the riser cable between floors are run separately and spliced in the junction boxes.

Terminal Boxes. The terminal boxes in which the subsidiary cables end must be large enough to accommodate the necessary connecting blocks. In most cases, boxes 18 inches square by five inches deep (inside dimensions) are sufficiently large. These boxes are installed on each floor as near the wiring center as possible, and, where there is a conduit system on the floor, they are connected with each office by a $5 / 8$ inch or $3 / 4$-inch conduit which ends in the office at an outlet located either at the baseboard or the molding. Outlets should be located at the baseboard when it is of wood. If the baseboard is of metal or marble the outlet should be located at the molding.

In many cases owners of buildings do not desire to install conduits from the subsidiary boxes on each floor to every office. By providing suitable moldings, properly arranged to carry the individual pairs between the subsidiary boxes and the offices, wiring that is practically concealed can be done without the expense of conduits, and as the wiring is permanent only as far as the subsidiary boxes, the system is flexible enough to allow a suitable distribution of cable wires among the various rooms on a floor.

Where this plan of wiring is employed the subsidiary boxes may be made smaller than where individual conduits to the rooms are installed. The following table shows the outside dimensions of the present standard sizes of subsidiary boxes:

\begin{tabular}{|cc|c|c|c|}
\hline \multicolumn{2}{|c|}{$\begin{array}{c}\text { Number of pairs of wires } \\
\text { terminated in box }\end{array}$} & $\begin{array}{c}\text { Height of box in } \\
\text { inches }\end{array}$ & $\begin{array}{c}\text { Width of box in } \\
\text { inches }\end{array}$ & $\begin{array}{c}\text { Depth of box in } \\
\text { inches }\end{array}$ \\
\hline Regular & Extra & & & \\
10 & 1 & $12 \frac{1}{2}$ & $6 \frac{1}{4}$ & $2 \frac{5}{8}$ \\
15 & 1 & 16 & $6 \frac{1}{2}$ & $2 \frac{5}{8}$ \\
20 & 1 & 21 & $6 \frac{3}{4}$ & $2 \frac{7}{8}$ \\
30 & 2 & 16 & 12 & $2 \frac{7}{8}$ \\
40 & 2 & 21 & $12 \frac{1}{2}$ & \\
\hline
\end{tabular}

Fig. 2 shows a front elevation and section of one of these boxes. The equipment consists of a connecting block strip and a form or fanning strip. The connecting block is of insulating material and carries a pair of binding posts for each pair of cable wires to 
be terminated in the box. The form strip is of wood and serves merely as a guide to preserve an orderly arrangement for the individual twisted pairs that run from the telephone to the box. These twisted pairs pass through holes in the form strip and are secured under the nuts and washers of the binding posts as are also the wires of the cable.

Cross-Connecting Boxes. Where a private branch exchange switchboard is to be installed, a cross-connecting box will be required. The wiring center in a case of this kind is at the crossconnecting box and not at the private branch exchange switchboard.

Use of Moldings. As shown in Fig. 2, the subsidiary boxes

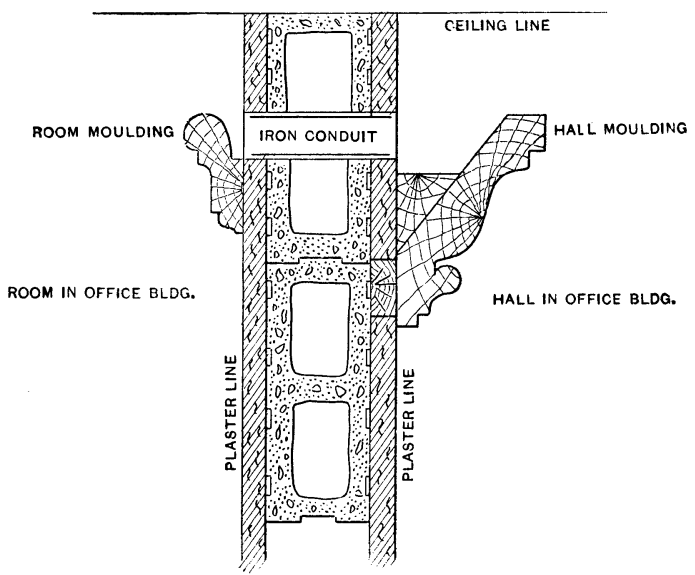

Fig. 3.-Cross Section of Partition Showing Hall Molding, Room Molding and Partition Conduit.

are placed near the ceiling and wide shell molding, Fig. 3, should be provided in the halls for carrying the paired wires from the subsidiary boxes to the rooms. A smaller molding should also be provided in the individual rooms for carrying the wires to the particular locations desired. The space for the wires at the tops of these moldings should not be enclosed but should be left open. The object is to provide a continuous trough from each subsidiary box reaching out to every room that is to be fed from it. Fig. 3 illustrates a section of one of these moldings.

Where it is necessary to make a concealed run across the ceiling of a hall, in order to avoid carrying exposed wires across the finished ceiling or to obviate making a circuitous run around the 
hall to reach rooms on the opposite side from the subsidiary box, conduit should be laid in the ceiling before the plastering is completed to enable a small cable to be carried across the hall to provide for such lines. (Fig. 4.)

Where the wires enter a room from a hall molding, a piece of $3 / 4$-inch conduit should be placed in the partition to enable the wires to be carried through it from the molding in the hall to the molding in the room. This avoids the necessity for drilling holes through the partition after the building is completed, which would be likely to result in damaging the finished wall. The conduit should either be lined with insulating material or the sharp edges around the inside of the pipe should be rounded off. (Fig. 3.)

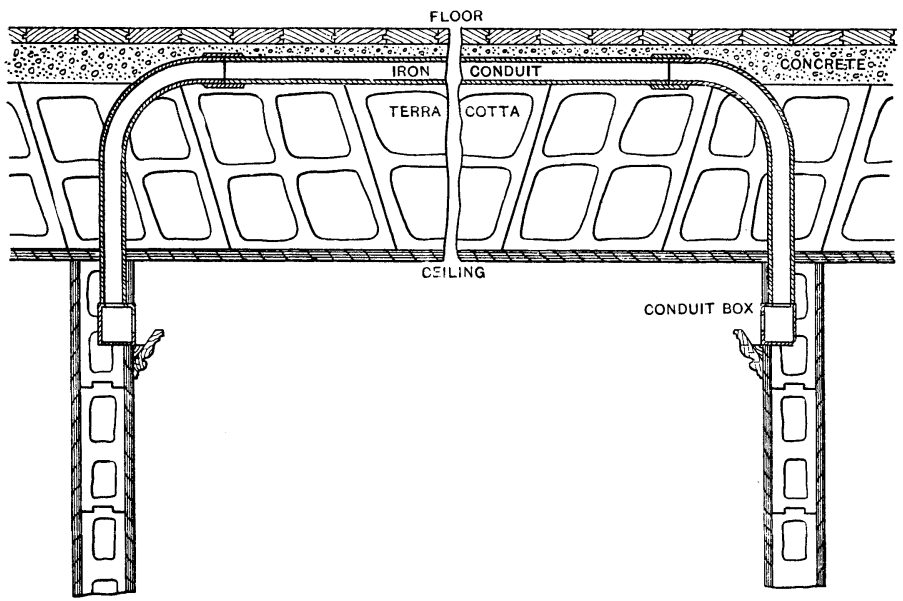

Fig. 4.-Method of Placing Iron Conduit Across Ceilling of HALL.

Kind of Cable. Paper insulated lead covered cables, such as are used by telephone companies in their outside plant, are the most desirable for use in building work. These cables are smaller and less costly for the same number of wires than cables of rubber insulated wires. With this type of cable all of the terminals must be made with lead covered silk and cotton insulated cable, boiled out in beeswax or approved compound, and carefully shellaced, as the paper insulation will not stand handling if exposed, and moisture must be prevented from entering the paper insulated cable. Should the terminal of necessity be in a particularly damp location it must be made with rubber covered wires. 
General Arrangement of Riser and Subsidiary Cables. From what has already been said it will be seen that the general arrangement of riser and subsidiary cables is practically the same irrespective of whether conduits or shafts and moldings are provided.

The splicing of the subsidiary cables for each floor to the riser cable is usually done so that a given pair of wires in the riser cable is available for use on more than one floor. This is termed "bridging" the conductors and furnishes a multiple system of distribution. By this means the flexibility of the system is increased and fewer spare pairs need be provided in the riser cable than would be required if there were no "multipling."

From records of a large number of house cable systems it has been found that by bridging about two-thirds of the pairs in the riser cable at the subsidiary branches the most advantageous balancing of facilities is obtained. If less bridging is done it often happens that many of the subsidiary cables become congested before the riser cable. Owing to the use of standard size cable it is frequently necessary to make either risers or subsidiaries somewhat larger than the exact number indicated by the density study. The use of such cables may cause the proportion of bridging to vary from one-half to three-quarters.

In splicing the subsidiary cables to the riser cable in buildings of moderate size, it is not economical to open the large riser cable on each floor. In such cases, the plan followed is to take out from the riser cable at one floor the small subsidiary cables for several floors and to carry them from that point up or down to their respective floors.

Methods of Installation. If the riser cable is placed in a shaft the main cable and its subsidiary branches are often spliced together on the roof of the building or in some upper story and then lowered into place. In some cases the splicing is done in the telephone company's shop and the cable shipped to the building ready to be installed.

For supporting the cable a steel strand is used. Two or three wraps of iron wire are made about the cable at frequent intervals and these are attached to the strand by separating the individual wires of the latter and passing the tie wires through the interstices of the strand. If the subsidiary cables are more than about 30 feet in length only a short section of each is spliced to the riser cable before lowering. In this case the subsidiary branches are run and spliced to these stubs after the riser is put in place. 
Special Conduit Work. In the methods above described the facilities provide for locating the telephones on or near walls or partitions, as this is the most common location. It can sometimes be foreseen by owners or architects that telephones will be required at some distance from a wall or partition, as would be the case with a desk placed in the center of the room. Where an arrangement of this kind is desired the owner should provide a duct in the floor extending trom the location of the telephone to the picture molding on the wall or to some other place easily accessible for wiring. A duct of this kind should end at the floor in a floor box covered with a flush plate.

It sometimes happens, particularly in buildings used by large corporations or firms, that entire undivided floors are occupied by large numbers of desks. Telephone service is frequently required at all, or a large part of these desks and the locations and arrangement of the desks on the floor may from time to time be changed. The floors of these buildings are often of fireproof construction. To meet a situation of this kind adequately it is necessary to be able to carry individual pairs of concealed wires to desks placed at any points on the floor, so that great difficulty and expense would be encountered in providing concealed wiring if suitable facilities admitting of the utmost flexibility were not provided in advance.

The best method of doing this is to carry branches from the riser cable in conduits to convenient building piers, placing subsidiary junction boxes at the bases of these piers. The entire floor is then provided with small floor outlets placed at the corners of squares about eight feet a part, each outlet being connected by conduit in the floor with the nearest subsidiary junction box at a building pier. Where the floors are not of fireproof construction, the individual pairs of wires are run in small channels grooved out of the floor beams on their upper surface. The locations of these channels should be accurately marked above the finished floors. Small brass nails are convenient for this purpose. When a telephone is required at a desk the flooring over the nearest channel is cut through, thus establishing a connection through the channel with a subsidiary terminal, conveniently placed, the wires being fished through the channel in the ordinary manner.

Arrangement of Conductors to Insure Flexibility in Operating the System. In order that the main terminal box may be as small as practicable the number of cross-connections to be made 
in it should be kept at a minimum. This is also important from maintenance considerations. To enable this to be done the method of distribution is arranged in a similar manner to that employed in other portions of the telephone plant. A certain number of pairs of wires in the riser cable are directly connected to the cable entering the building from the telephone exchange. These connections are made in a lead covered splice and the pairs of wires thus spliced directly through do not appear in the main terminal box.

Certain other pairs in the riser cable are brought to terminals in the main terminal box. The remainder of the pairs in the riser cable are directly spliced to pairs in the exchange cable and these same pairs are also brought out by means of a branch splice to terminals in the main terminal box. If there are any extra pairs in the exchange cable that are not directly spliced to pairs in the riser cable they also are terminated in the main terminal box.

This arrangement, if the pairs have been skilfully distributed, permits of great flexibility and reduces to a minimum the number of cross-connections required in the main terminal box. The pairs that are connected straight through from the exchange cable to the riser cable without appearing in the main terminal box are used for the direct line telephones in the building and for private branch exchange trunk lines. The pairs of the exchange cable that appear in both the main terminal box and the riser may be used, first at the various floor boxes in the event of the congestion of the direct exchange pairs that appear in these boxes, and second in the main terminal box for battery and generator circuits and for overflow of business, due to erratic growth in lines on the various floors in the building, by crossconnecting to the house cable conductors extending to these floors. House cable pairs terminating in the main terminal box are used for private lines and miscellaneous circuits and for providing battery and generator circuits between the box and the various private branch exchanges by cross-connecting to the exchange cable in the main box.

\section{Examples of OfFice Building Wiring}

The Hudson Terminal Buildings in New York City, extending from Cortlandt to Fulton Streets, one block west from Broadway, afford an example of the facilities required for telephone service in the case of office buildings of the largest size. The two Terminal buildings are treated as a unit so far as the telephone wiring 
PLATE LXXXVII

A. I. E. E.

VOL. $X X X I$, NO. 7

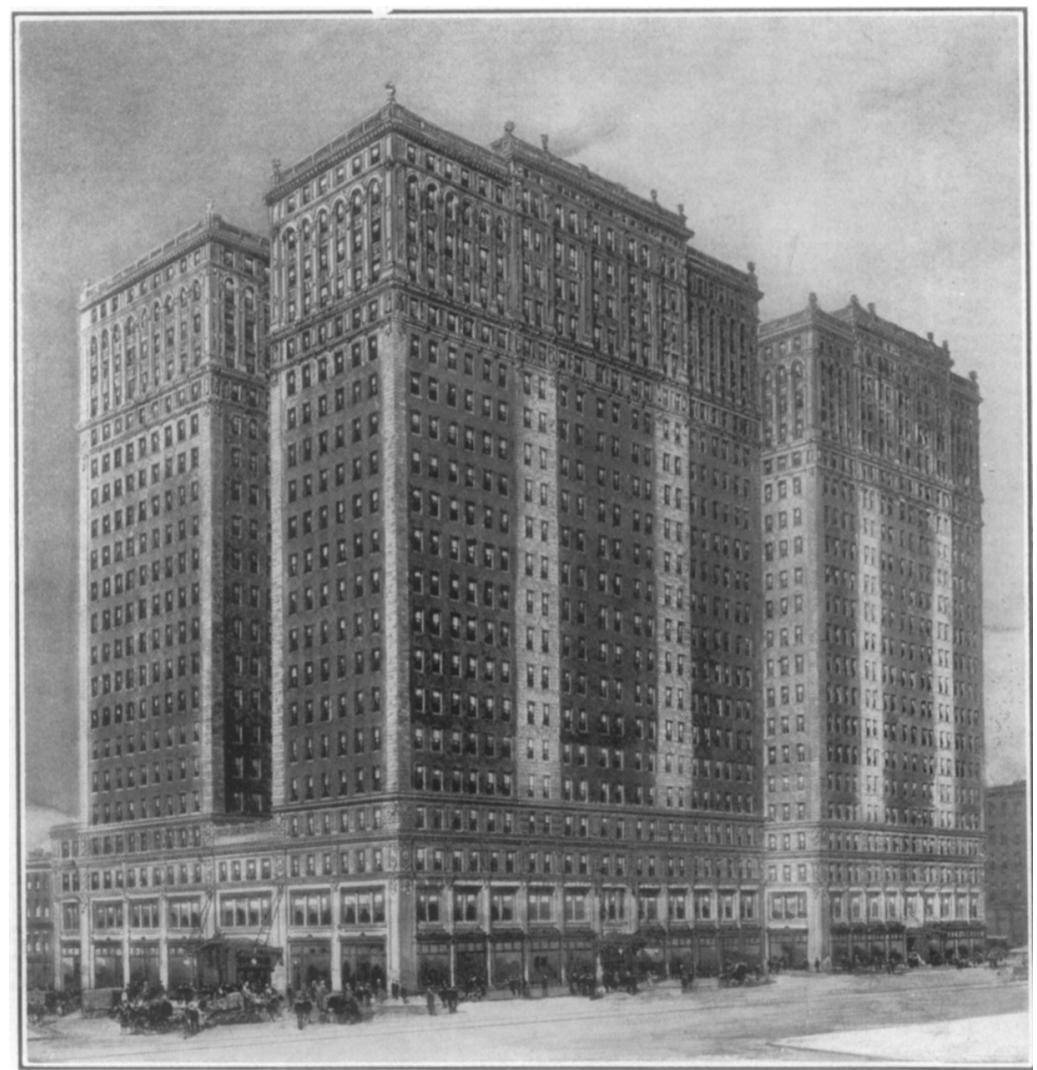

Fig. 5. - Perspective View of Terminal Buildings, [RHODES: NEW YORK CITY: 
is concerned. Together they contain nearly a million square feet of renting area and at the present time have about 3,000 telephones. These data, with Fig. 5, a perspective view of the buildings, will indicate the magnitude of the wiring problem.

The cabling and wiring of these buildings is illustrated by the following figures:

Fig. 6 is an elevation of the riser cables, showing the connections with the exchange cables and the general arrangement of the branch cables to each floor. Fig. 7 is a detail elevation showing typical "multipling" of the branches from the risers to the floors and of the subsidiary cables on the floor. Fig. 8 is a typical floor plan showing the locations of the riser cables, the floor cables, the floor terminals and the wire runs in the hall moldings to each office.

At the present time there are three 606-pair underground cables extending from the telephone central office to these buildings. The central office cables are spliced to the house cables near the main terminal. About 16 per cent of the pairs in the central office cables are connected directly to pairs in the riser cables that do not terminate at the main frame terminal of the buildings. The remaining 84 per cent of the pairs in the central office cables are bridged to pairs in the riser cables which also appear at the main frame terminal. All pairs from the central office cables that are directly connected to house cable pairs are marked $D F$. All pairs from the central office cables that are connected to house cable pairs that also appear at the main frame terminal are marked $F$. The balance of the pairs in the house cables (marked $H$ ) have no connection with pairs in the central office cables except by cross-connection at the main building terminal, where they may be connected as desired to pairs in the central office cables that are also bridged to riser cable pairs.

As new cables to the central office are added to meet the demand for additional telephone service in these buildings, the existing central office cable requiring relief will be left directly connected to the riser cable system and the bridged pairs will be transferred to the new cable.

The riser cables, of which there are five in all, are located in cable shafts beside the elevator shafts, Fig. 8. On each normal floor are provided conduits extending from the cable shaft to each of the five subsidiary terminals on that floor. In Fig. 8 these conduits and the subsidiary terminals are shown by solid lines. Broken lines represent the runs of individual twisted 


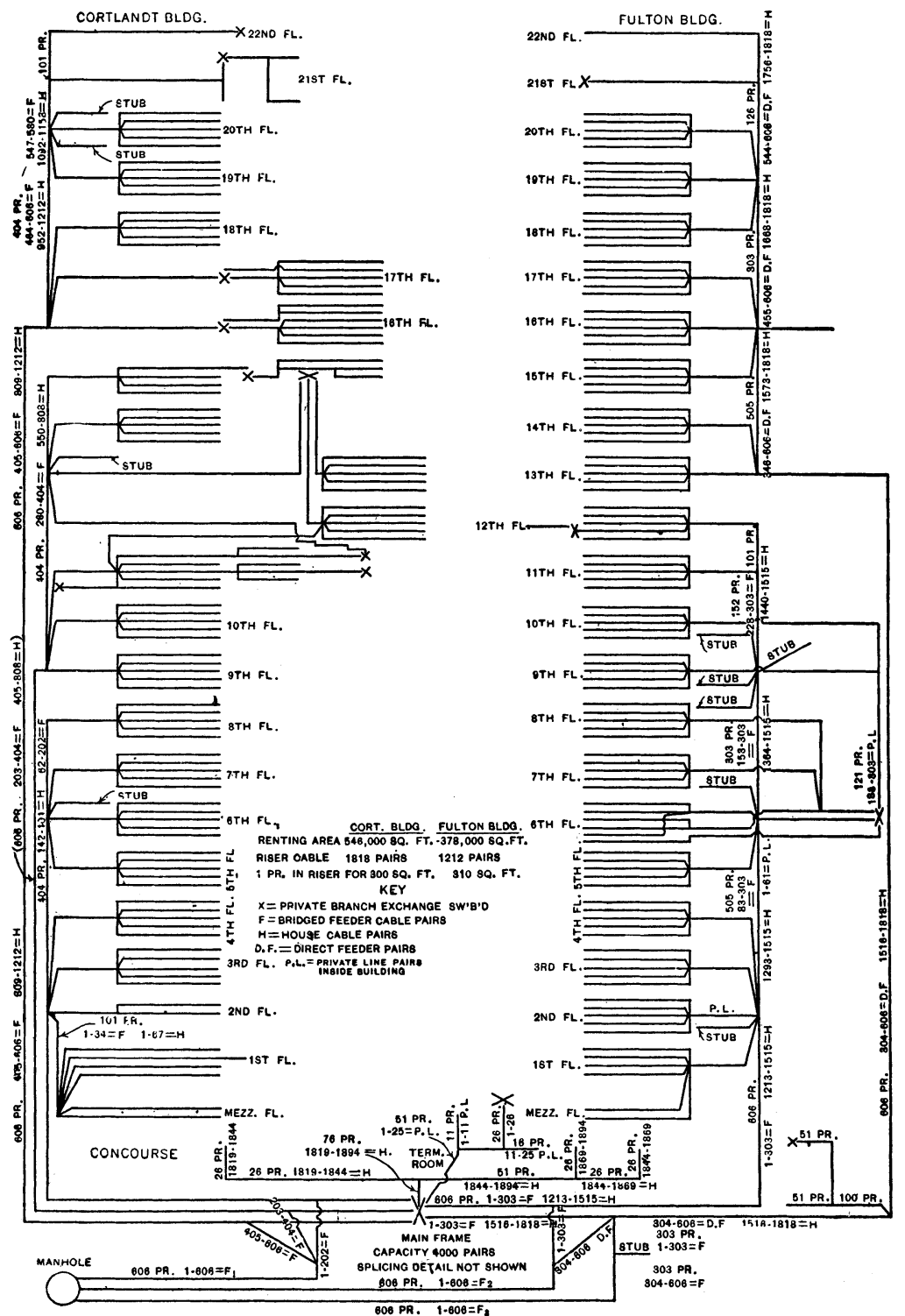

Fig. 6.-Terminal Buildings, House Cable Distribution. 
pairs of wires in moldings from the subsidiary floor terminals to each office on the floor.

On account of its complexity, the entire scheme of multiple

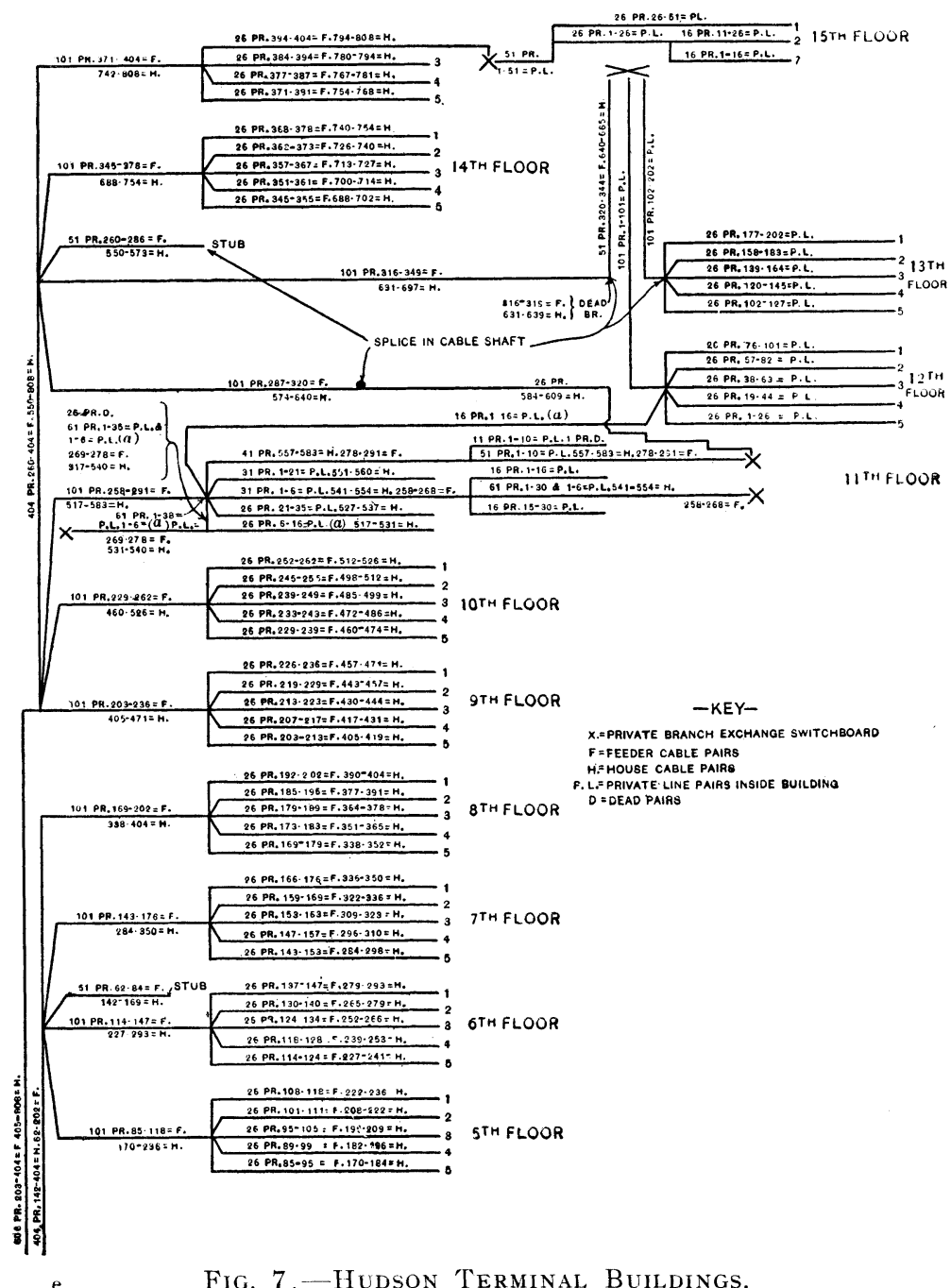

D tailed distribution of cable pairs on the 5 th to 15 th floors, inclusive, in Cortlandt St. Building.

distribution for these buildings is not shown in full detail. The principles are, however, illustrated in Fig. 7 which shows the complete lay-out of the distributing cables branching from two 
points of the riser cable system of the southernmost (Cortlandt) building and feeding from the fifth to the fifteenth floors, inclusive. The distribution for the fifth to eighth floors inclusive represents one of the simplest cases in these buildings. That for the ninth to fifteenth floors is one of the most complicated due to the special demands brought about by certain private branch exchange requirements.

In portions of these buildings, on account of private branch

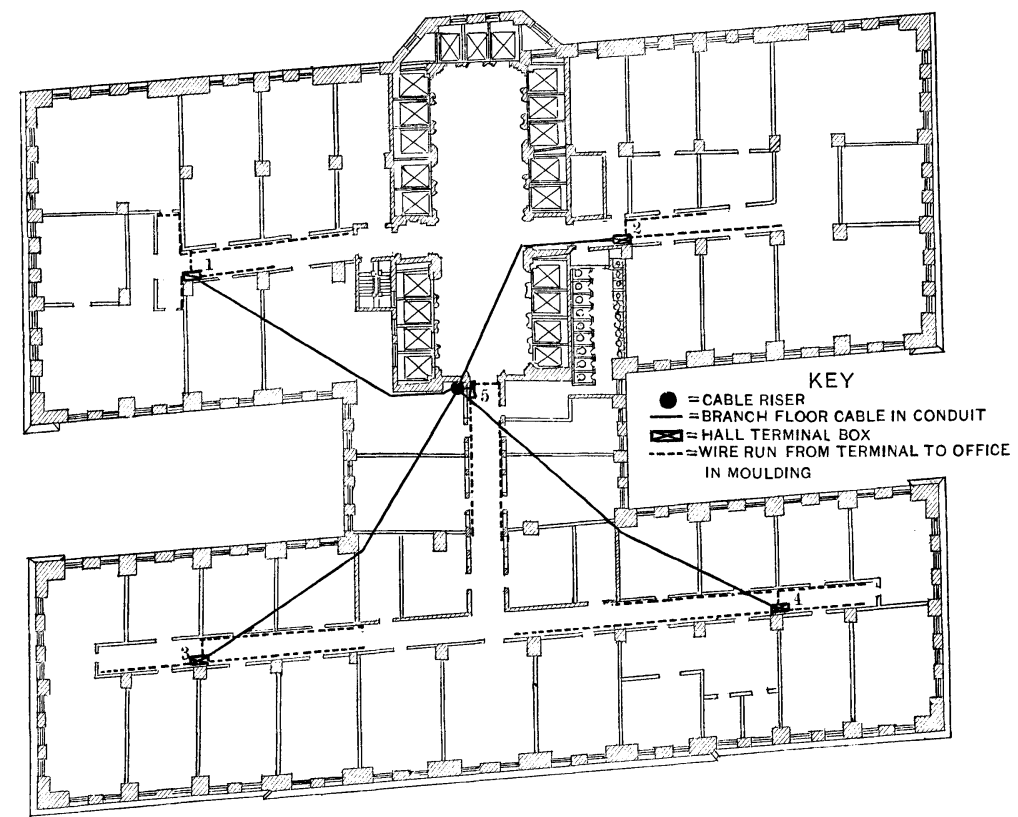

Fig. 8. - Terminal Buildings-Typical Floor Plan in Cortlandt BUILDING.

exchanges, some of the floor distributing branches from the riser cables that would be needed to supply individual tenants, are not required at the present time. Stubs containing the cable pairs that would normally appear on these floors are, however, provided and left in the cable shaft so that, merely by splicing subsidiary cables to these stubs, service on these floors of a different character could readily be established if changed office conditions should render this necessary.

The requirements for telephone service in these buildings are 
so large that a main distributing frame is installed to act as the main building terminal. This frame serves the same purpose as the terminal box equipment shown in Fig. 1, namely to enable the pairs from the central office cables to end in a compact series of terminal lugs, and the pairs from the house cables in another series of terminal lugs; the lugs being so arranged that, by short lengths of twisted pair wire, cross connection can readily be made between any pair brought to the frame from the central office cables, and any pair brought from the house cables. This permits great flexibility of distribution. In the "multipling" diagrams, Figs. 6 and 7, the numbering of the pairs in the house cable system is on the basis of two groups. All feeder pairs in the house cable system, whether directly spliced to pairs in the central office cables and not appearing at the main terminal or bridged to pairs in the central office cables and also appearing at the main terminal, are numbered from one up and designated either $D F$ for direct feeder or $F$ for bridged feeder pairs.

All pairs in the house cable system that terminate at the main terminal without being directly connected or bridged to the central office cables are numbered as a separate group from one up and are designated $H$ for house pairs.

Eleven Story Store and Office Building. This building is chosen as an example of a complete conduit installation. Fig. 9 is a plan of one of the office floors and Fig. 10 shows elevations of the conduit system and the cable system. The diameters of the conduits are indicated in order to show how the conduits decrease in size with the cables as they rise up through the building.

Owing to the lower portion of this building being arranged for stores, the office distribution on certain of the riser cables does not begin until the sixth floor is reached.

\section{LofT BUILdings}

Conduits for wires or cables are rarely provided in loft buildings. The riser cables are placed in shafts and the wires are distributed on each floor along the baseboards. The wire center on each floor is usually at the bascboard near the passenger elevator shaft. Although this arrangement is undesirable in many cases, it is difficult, on account of the floors being undivided and the locations of the telephones not being known until the premises are occupied, to make any provision in advance for distributing the wires. A system of conduits and floor boxes would be expensive and is not considered necessary. 
Where one firm occupies the entire loft building, the size of the riser cable is determined entirely by the equipment of the private branch exchange switchboard and the probable future requirements of the firm as to telephone service. In a case of this kind the center of the wire system is at a cross-connecting box located close to the private branch exchange switchboard.

A modification of the method of distribution already described for office buildings is usually employed in loft buildings. The riser cable is divided into two parts termed "bridged feeder"

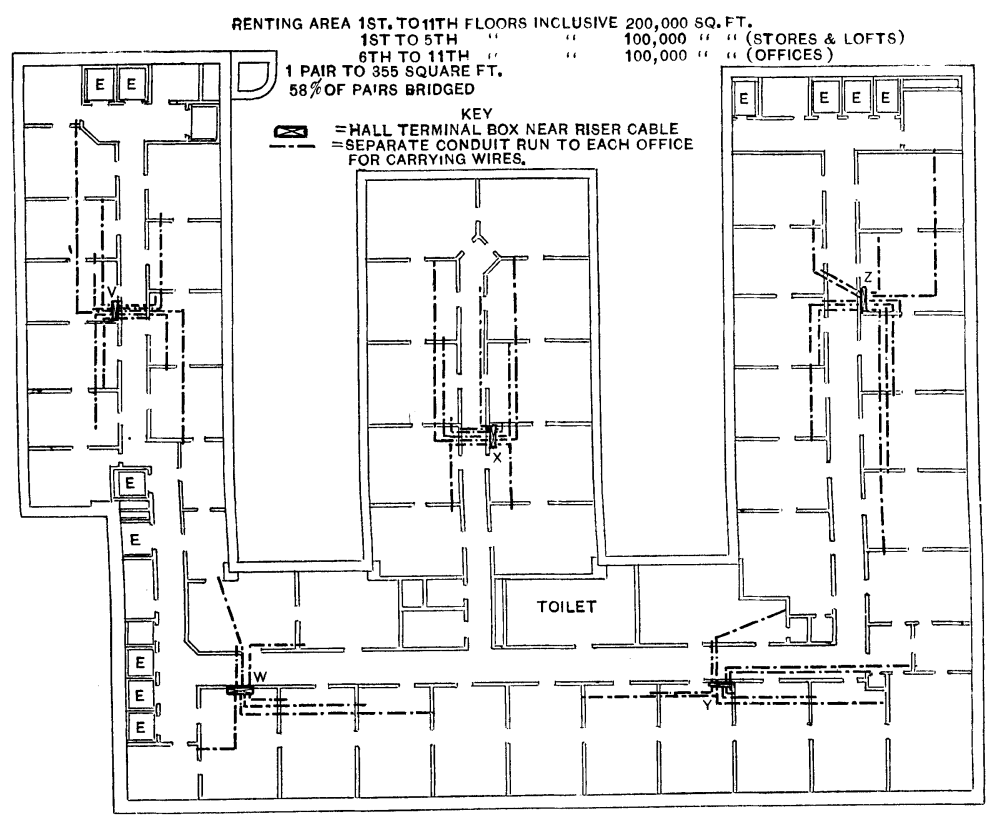

Fig. 9.-11-Story Office Building, Typical Floor Plan.

and "house cable." The house cable pairs are terminated in the main terminal box near the foot of the riser, and the bridged feeder pairs are directly connected to pairs in the exchange cable and also by a branch splice are terminated in the main terminal box.

Example of Loft Building Wiring. Fig. 11 shows the floor plan and cable distribution of a twelve story loft building. It will be noted that the arrangement of pairs does not agree with the preceding statement that in loft buildings the riser cable is divided only into bridged feeder and house cable groups. This 
KEY

$X=F R I V A T E$ BRANCH EXCHANGF SWITCHEOARD

$F=$ FEEDER CAELE PAIRS

$H=$ HOUSE CABLE PAIRS

$D=D E A D$ PAIRS

P... = PPIVATE LINE INSIDE BUILDING

3. $F .=B R I D G E D$ FEEDER PAIRS
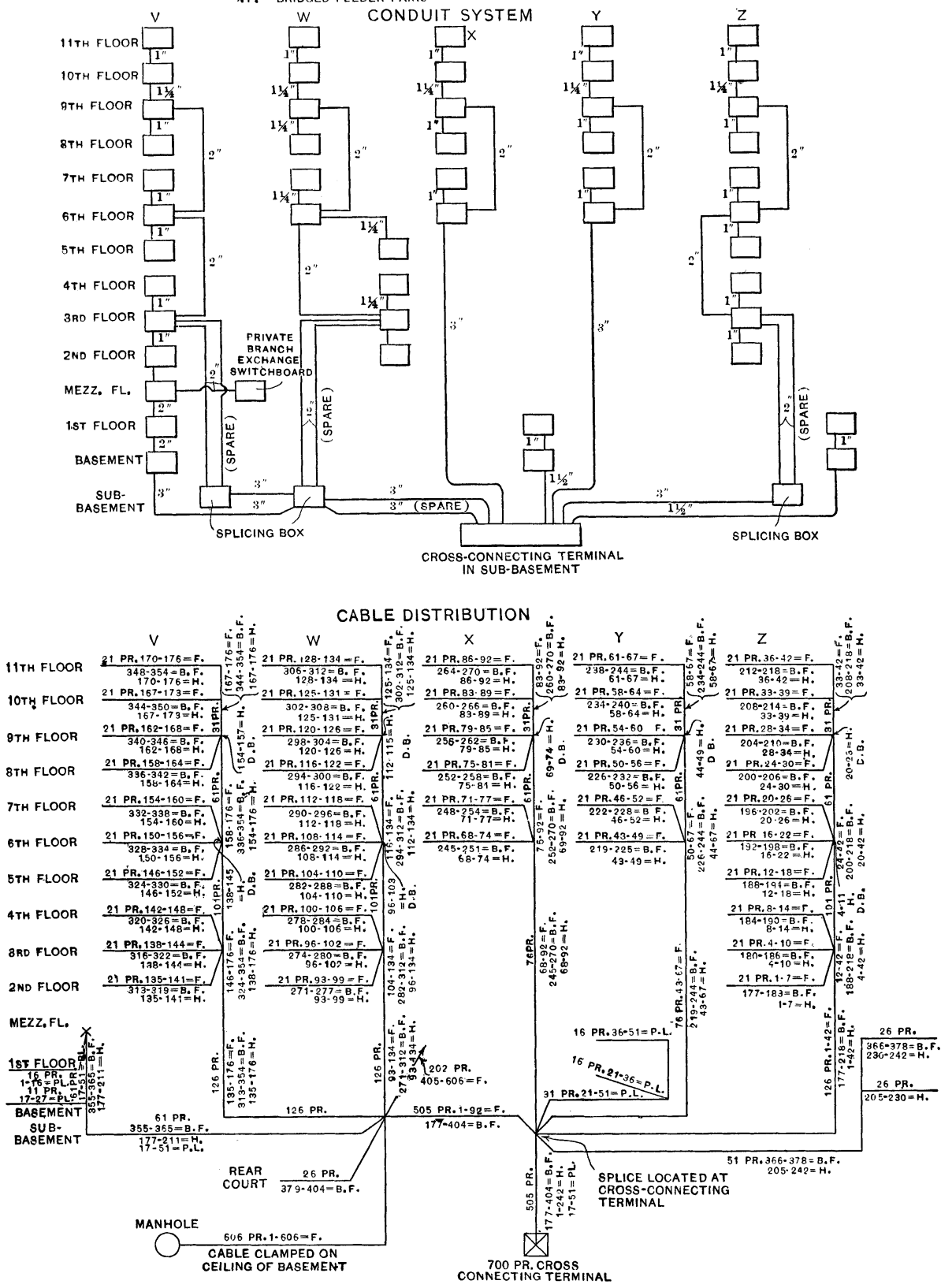

Fig. 10.-11-Story Office Building, Conduit System and Cable Distribution. 
diagram shows, in addition to these groups, certain direct feeder pairs. The reason is that it is expected that this particular loft building will sooner or later be partitioned off for office use, and this condition has been anticipated in planning the cable distribution.

\section{Hotels and Apartment Buildings}

General Scheme of Wiring. The telephone systems for hotels and apartment buildings differ from those for office and loft buildings in one important respect. Hotels and apartment buildings can be wired in advance on a permanent basis on account of the probability that there will be no essential change in the number of wires needed, the ultimate requirements being

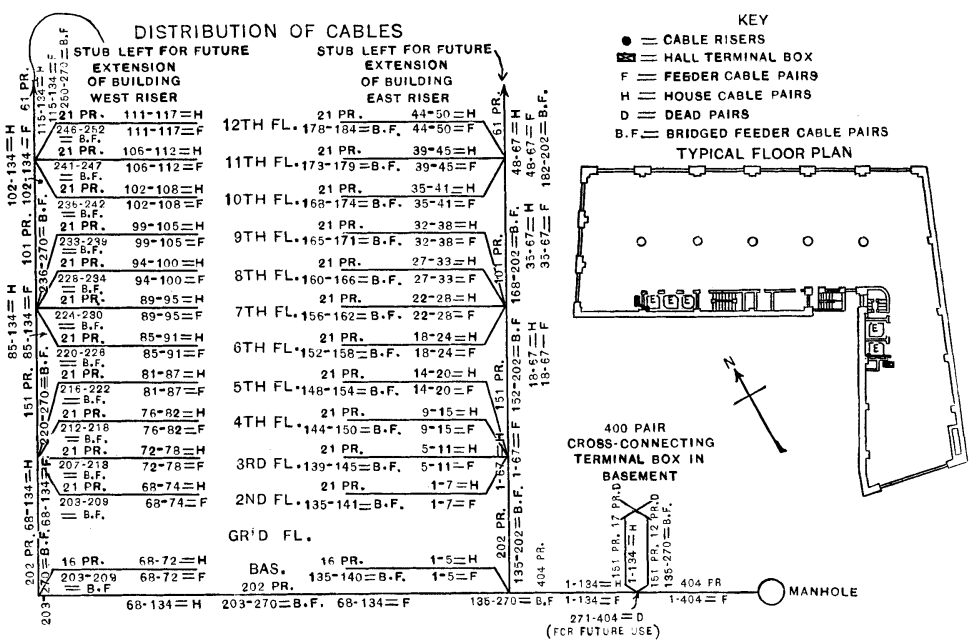

Fig. 11.-12-Story Loft Building.

closely determined by the number of rooms or apartments. The locations for the telephones in the various apartments or rooms are also generally permanent and the relative locations of the telephones are the same on each floor.

The telephone system installed in these buildings consists of a private branch exchange switchboard located at some convenient point, usually on the ground floor. In hotels this private branch exchange switchboard is placed in or near the office. Telephones are installed in each room or apartment and wired to this switchboard. The latter is connected by the necessary number of trunk lines with the nearest central office of the telephone company. 
The wiring problem is simple in comparison with that in office buildings. It consists of running a pair of wires from the telephone location in each room or apartment to a common center in the cross-connecting box near the private branch exchange switchboard. It is important to make provision so that the telephone company can run its wires from the cross-connecting box of the privatc branch exchange switchboard to some point in the basement where connection can be made to the central office cable. The latter cable is generally not run in conduit but is clamped to the ceiling of the basement.

Subsidiary Conduit. Conduits for distributing wires on floors in hotels or apartment buildings should not ordinarily be over 50 feet in length nor should they have more than three bends with a minimum radius of five inches. Any conduit 100 feet in length should not be less than one inch in diameter: 5/8-inch conduit should be provided for a maximum of two pairs of wires and $3 / 4$-inch conduit should be provided for a maximum of four pairs of wires. For more than four pairs of wires it is preferable to run cable.

Hotels. In laying out the wiring system for hotels, in addition to one pair of wires for each room, as mentioned above, provision has ordinarily to be made for a small percentage of spares to provide for defective pairs and for a few direct lines.

From the wire center at the cross-connecting box near the private branch exchange switchboard a cable is extended through the basement or sub-basement to the foot of the riser shaft. The riser cable extends up this shaft as a diminishing cable with subsidiary terminals located at convenient points on each floor for reaching the various rooms. The wires are distributed on the floors either by molding or through conduits, as the case may be. In many of the modern hotel buildings complete conduit systems are provided for concealing the telephone wires and cables. In such cases the vertical conduits are installed at some central point and junction boxes are provided on each floor for splicing and terminating cables. From the junction boxes separate $5 / 8$ inch conduits are extended to each room. The outlets in the rooms should be located four feet 10 inches above the finished floor for wall sets, this having been found by wide experience to be the most satisfactory height at which to place the telephone. For desk stands the outlets should be at the baseboard near the proposed location of the telephone. Where the floor area and the number of rooms are large it is often economical to have more than one terminal box on a floor. 


\section{Examples of Hotel Wiring}

18-Story Hotel. Fig. 12 shows the floor plan of this hotel with the locations of the riser cables and the individual telephones in each room. The separate conduit runs from the riser terminals to the rooms are not shown in order to avoid confusion on the drawing. Fig. 13 shows elevations of the riser cables with the branches at each floor.

In this installation the riser cables (five in number) are placed in shafts and the wire distribution on each floor is in separate conduits to each room. It will be noted that no feeder pairs are provided in the riser cables.

17-Story Hotel. This is a complete conduit installation.

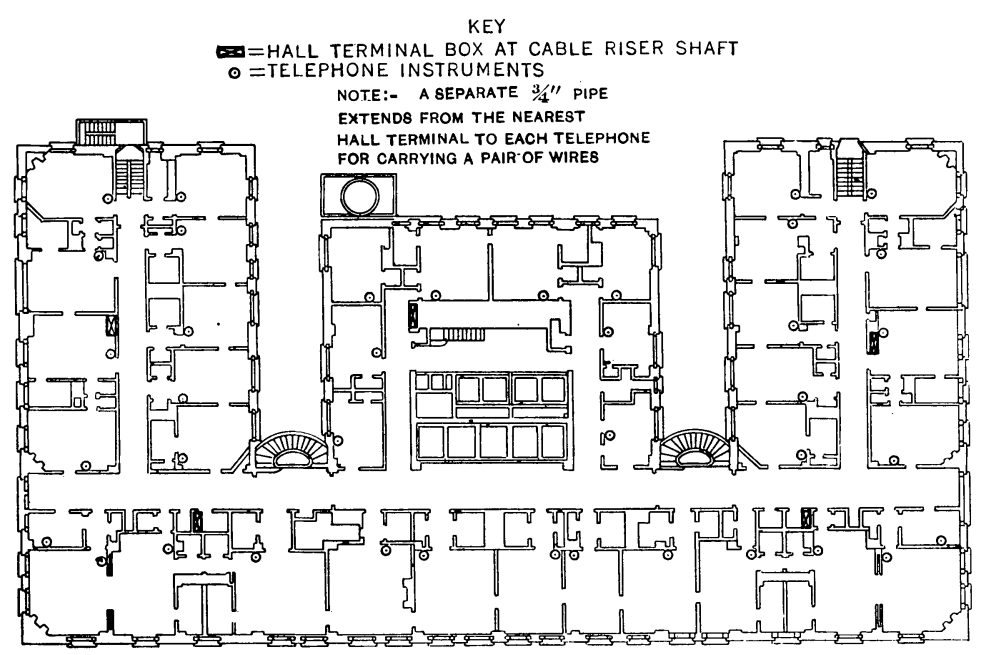

Fig. 12.-18-Story Hotel, Typical Floor Plan.

Fig. 14 shows the riser cable terminal boxes and individual telephone locations on a typical floor. Fig. 15 gives the elevation of the house cable system. This hotel has an apartment section which is cared for by the North riser cable. This section of the house has its separate switchboard. The other two riser cables feed the hotel portion of the house.

\section{Elevator Apartments}

Elevator apartment buildings are generally wired on the basis of two telephones to an apartment, one connecting to the private branch exchange switchboard and the other when desired, directly to the central office of the telephone company. 
In most of the high class elevator apartment buildings it is the practise of owners and architects to provide conduits for concealing the telephone wires and cables. In some cases a vertical shaft is provided instead of vertical conduit.

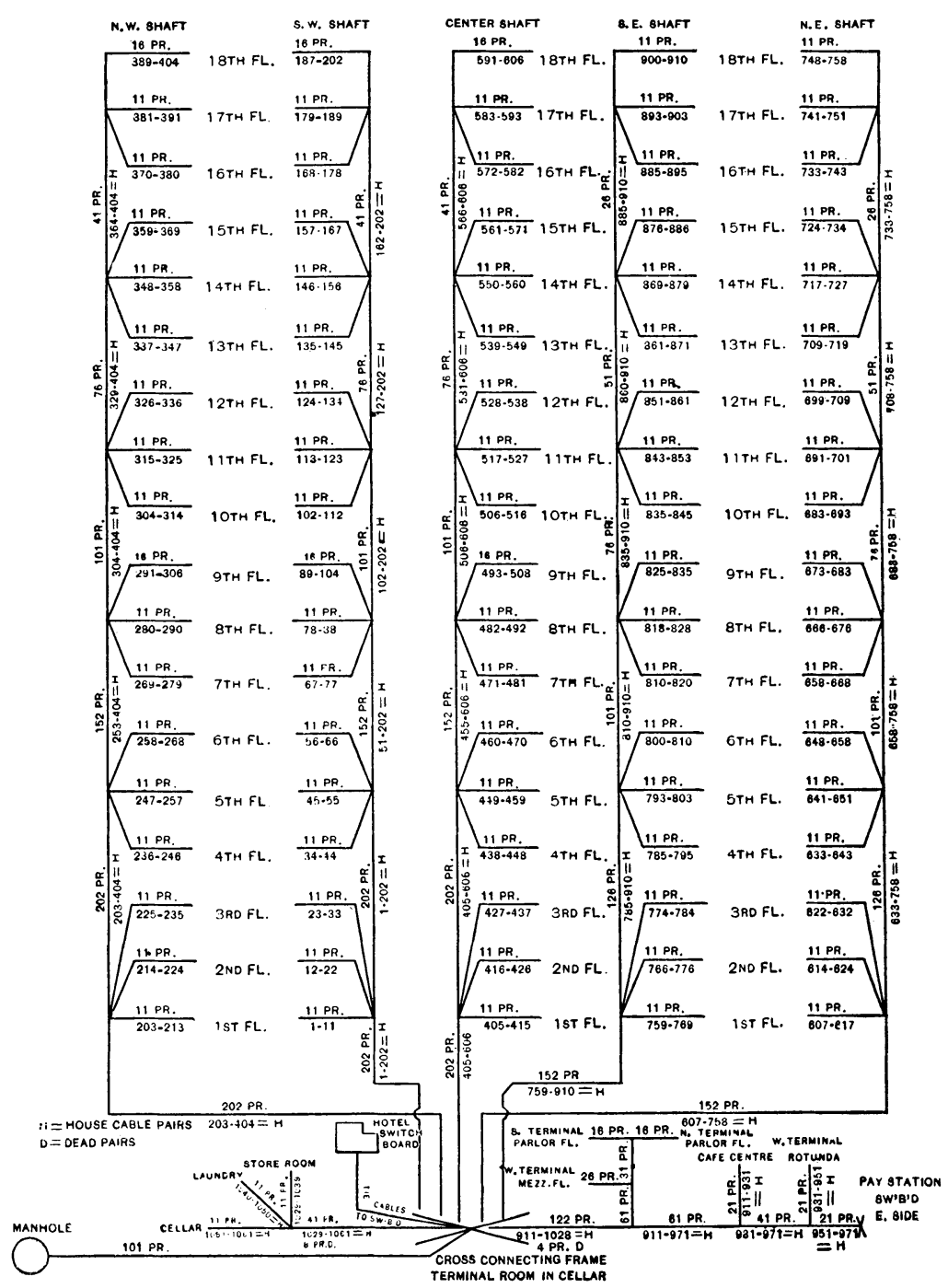

Fig. 13.--18-Storor Hotel, House Cable Distribution.

Where the floor space occupied by each apartment is small and the horizontal runs on each floor are short a riser or diminishing house cable is placed. This cable is extended up through 
the building in a conduit or a shaft, as the case may be, and branches containing a sufficient number of wires to provide two pairs for each apartment are terminated in junction boxes located at central points on each of the floors. From each junction box $5 / 8$-inch or $3 / 4$-inch conduits are extended to the location of the telephone in each apartment, the outlets being located, as in hotels, at the baseboards for desk telephones, and in the wall, four feet 10 inches above the finished floor, for wall telephones. This arrangement provides a flexible system, as the wires between the apartments and the subsidiary branches may be drawn in whenever service is required. As the horizontal run of conduit

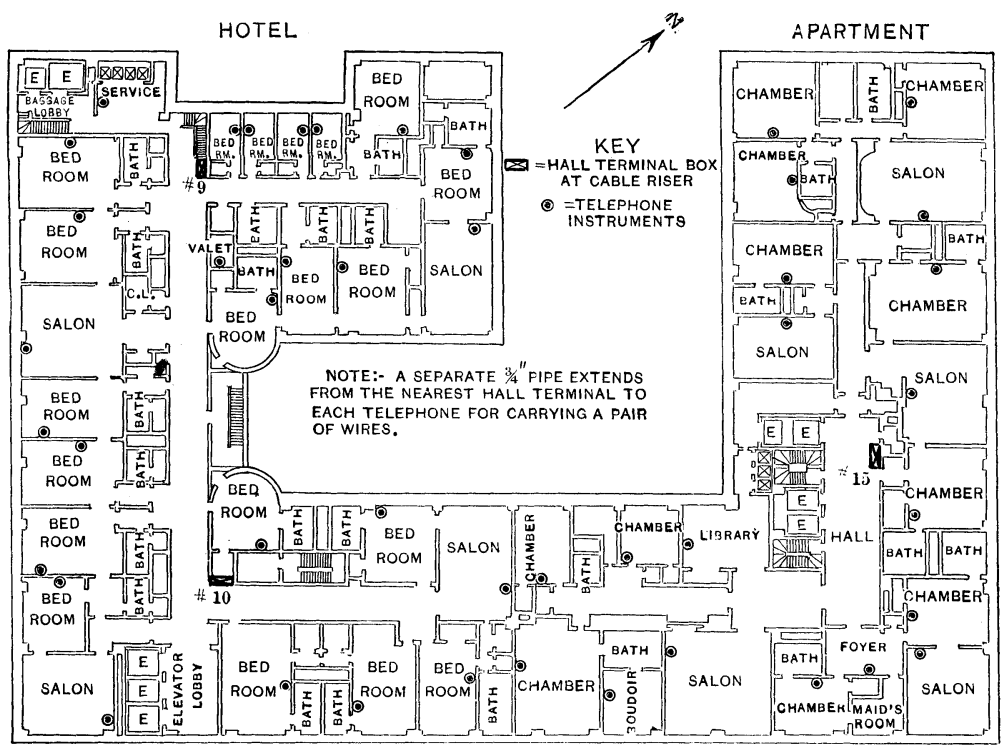

Fig. 14.-17-Story Combination Hotel and Apartment Building, Typical Floor Plan.

on each floor is comparatively short, the cost of the conduit installation is minimized. There is a further opportunity for economy in installing conduits from the junction box to the apartments, as it is frequently possible to use a single run of conduit for two apartments instead of a separate conduit to each.

In apartment buildings where the floor space occupied by each apartment is large, the above arrangement would necessitate long runs of small size conduit on each floor. In such eases, to avoid the excessive cost of this conduit, the wires are usually distributed to the apartments by a vertical system of conduits extending from the basement up through each tier of apartments. 
These vertical conduits diminish in size as they approach the upper portion of the building and the outlets in the apartments are located in the walls at the points where the telephones are to be placed.

In the basement, cables are extended from the cross-connecting box near the private branch exchange switchboard along walls and ceilings to the foot of each line of vertical conduits. At

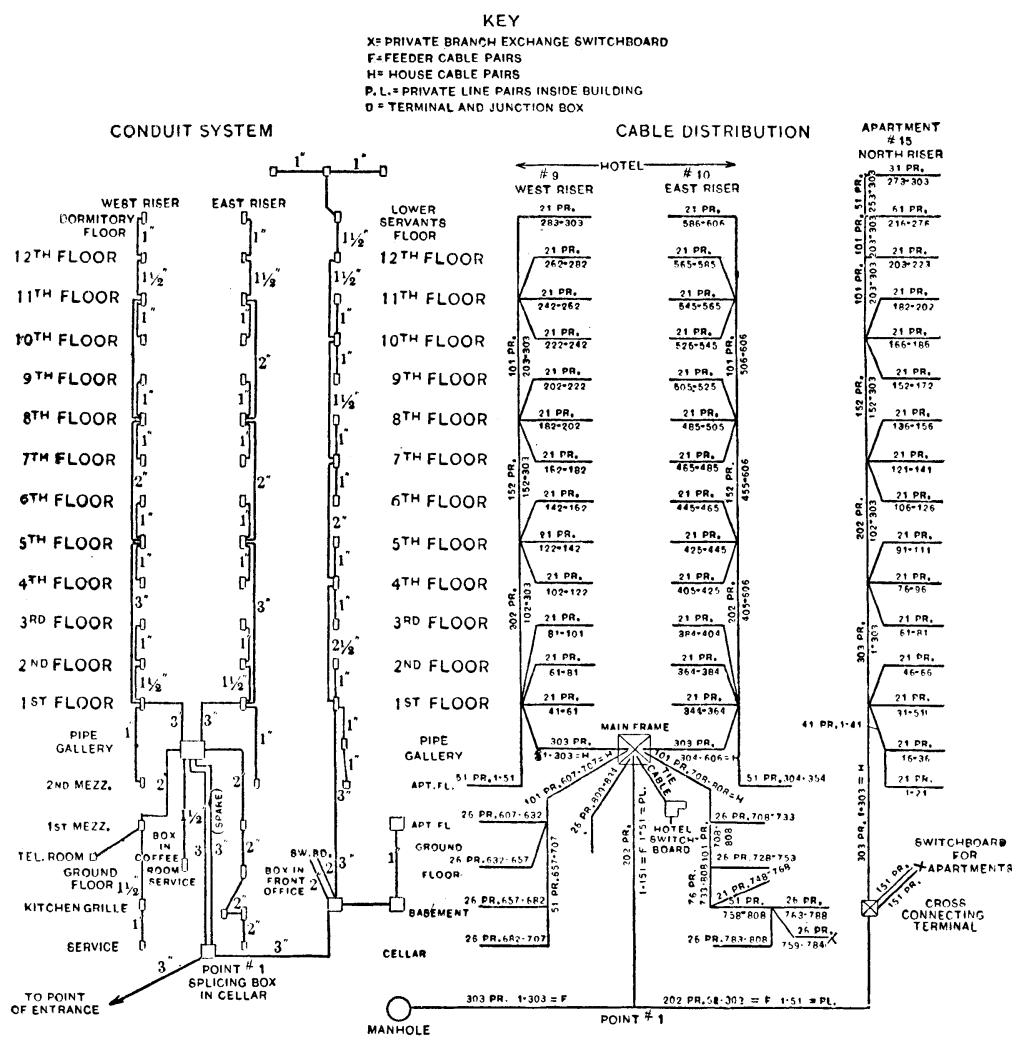

Fig. 15. - 17-Story Combination Hotel and Apartment Building, Conduit System and Cable Distribution.

these points terminals are established with sufficient conductors to provide two pairs of wires for each apartment to be cared for by the riser. The pairs of wires between these terminals and the apartments are pulled into the conduits as the service is required.

The size of the verical conduit varies with the number of apartments to be served. Generally a conduit two inches in diameter in the basement diminishing gradually to $3 / 4$ of an 


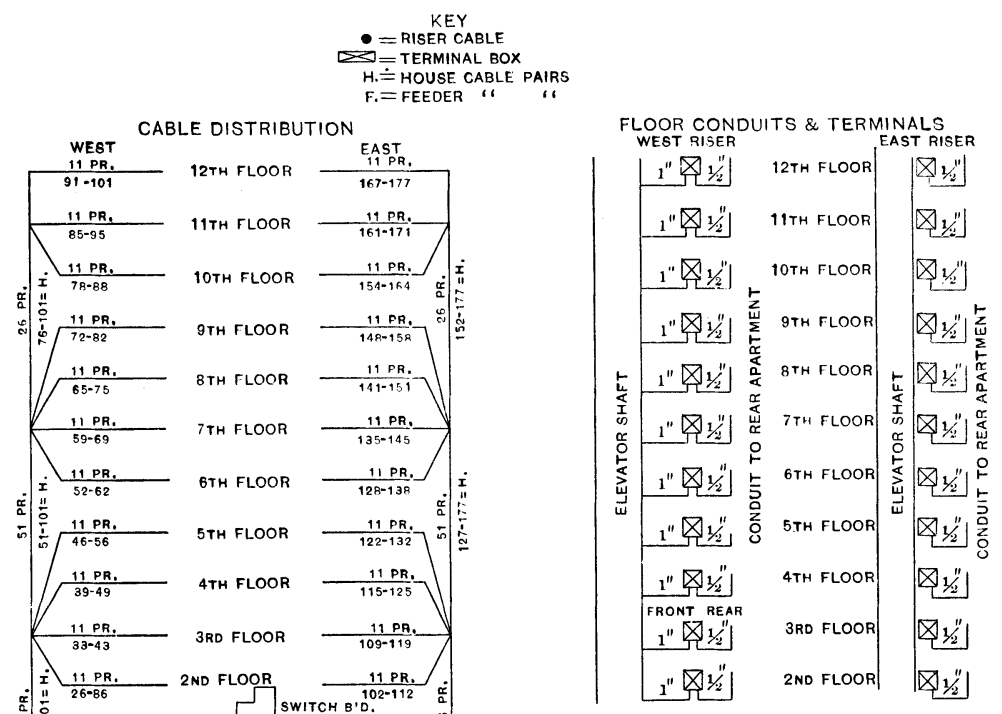

NOTE:- THE WIRES TO EACH REAR APARTMENT ARE CARRIED IN CONDUIT WHILE THE WIRES TO THE FRONT APARTMENTS ARE CARRIED IN MOULDING.

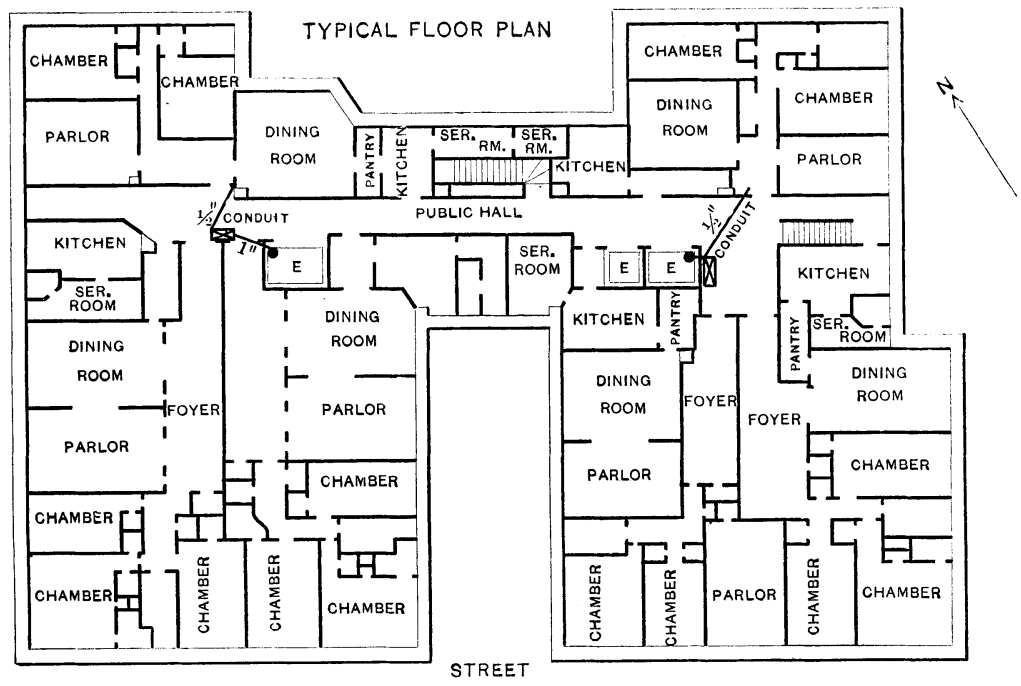

Fig. 16.-12-Story Elevator Apartment House. 
inch at the upper floor is sufficient to care for buildings 10 to 12 stories in height, and a conduit $1 \frac{1}{4}$ inches in diameter in the basement diminishing to $3 / 4$ of an inch at the top for buildings from six to 10 stories high.

The number of vertical lines of conduit depends on the number
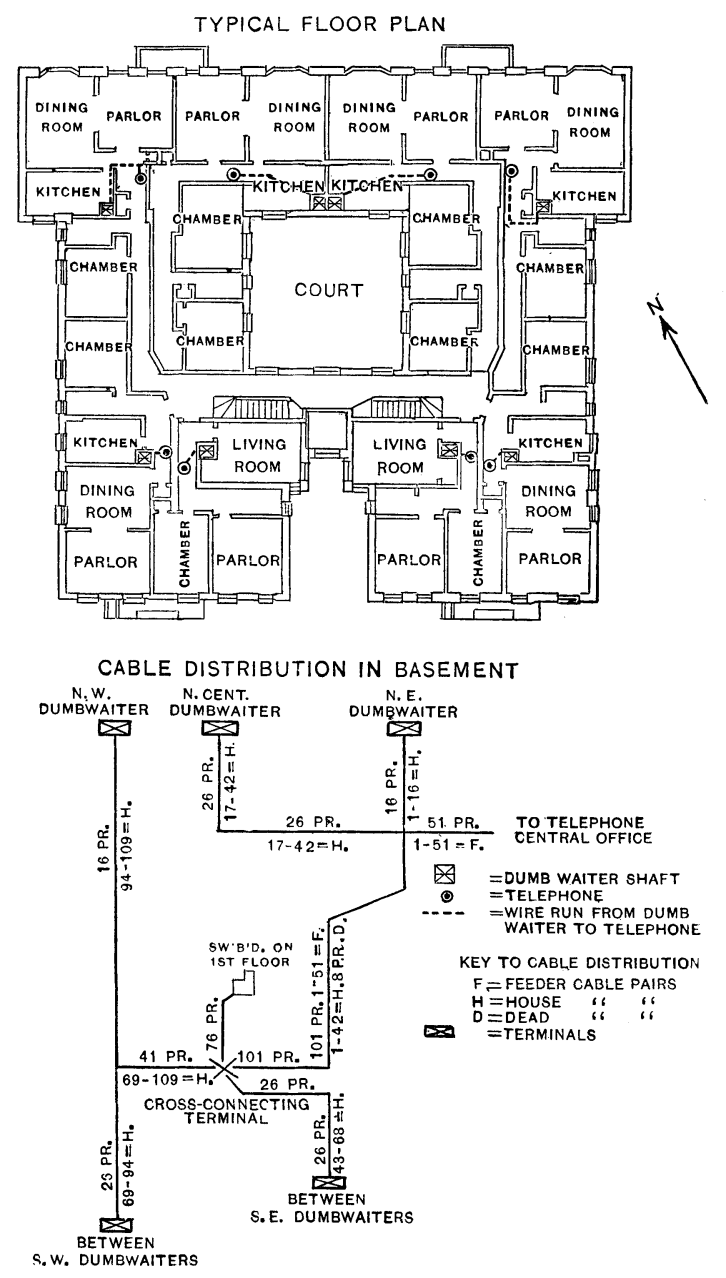

Fig. 17.-6-Story Non-Elevator Apartment House.

of apartments on each floor. Usually a separate line of conduits is required for each tier of apartments, but it is often possible to care for two adjacent apartments on each floor by a single line of conduit when the telephones in both apartments are to be placed on the dividing wall between them. This arrange- 
ment is, however, open to the objection that installers must gain access to one apartment for the purpose of installing the telephone in another. In spite of this objection, from the standpoint of the owner this method is probably the best for buildings of this class as it minimizes the cost of installation of conduits and is flexible enough to admit of direct lines being installed when such service is required.

Example of Elevator Apartment Building Wiring. Fig. 16 shows a 12-story elevator apartment building with six apartments to a floor and stores on the front of the first floor. The two riser cables are run in the elevator shafts.

A diagram is given showing the junction boxes on each floor and the sizes of the conduits used for distributing the wires on each floor.

\section{Non-Elevator Apartments}

Apartment buildings of the non-elevator class do not as a rule exceed five or six stories in height and frequently have as many as 10 apartments on each floor. Buildings of this class are wired by extending lead covered cables from the cross-connecting box near the private branch exchange switchboard through the basement to the foot of each dumb-waiter shaft where terminals are established. The terminals are made large enough to provide approximately for a direct line and an extension telephone for each apartment cared for by the dumb-waiter shaft, when it is thought that direct service will be required. The allowance made for direct line service depends upon the neighborhood. The wires to the various apartments are extended up through the dumb-waiter shafts from the terminals in the basement as service is required.

In some cases these buildings are wired in advance by forming the wires into a cable and taping the cable to protect it against mechanical injury, onc or two pairs being brought out at each apartment.

Example of Non-Elevator Apartment Building Wiring. Fig. 17 illustrates the case of a six-story apartment building having eight apartments to a floor. The wiring diagram shows the cable distribution in the basement to terminals at the foot of the dumb-waiter shafts.

The author wishes to acknowledge the valuable assistance of Mr. E. S. Worden and Mr. W. A. Taylor in preparing the illustrative examples of this paper. 